\title{
ILUMINAÇÃO NATURAL E EDIFÍCIOS RESIDENCIAIS VERTICAIS: ANÁLISES PARAMÉTRICAS A PARTIR DE CRITÉRIOS DAS LEGISLAÇÕES URBANO- CONSTRUTIVAS DA CIDADE DE SÃO PAULO
}

\author{
ILUMINACIÓN NATURAL Y EDIFICIOS RESIDENCIALES VERTICALES: ANÁLISIS PARAMÉTRICOS DE \\ LOS CRITERIOS DE LAS LEGISLACIONES CONSTRUCTIVAS URBANAS DE LA CIUDAD DE SÃO \\ PAULO
}

NATURAL LIGHTING AND VERTICAL RESIDENTIAL BUILDINGS: PARAMETRIC ANALYSIS FROM THE CRITERIA OF THE URBAN CONSTRUCTIVE LEGISLATIONS OF THE CITY OF SÃO PAULO

\section{BOSCARDIN, LUIZ}

Doutor em Arquitetura e Urbanismo pelo PPGAU FAU Mackenzie; São Paulo; Brasil. E-mail: luizarq@gmail.com

\section{FLÓRIO, WILSON}

Doutor pela FAUUSP em Tecnologia da Arquitetura, Professor Permanente do PPGAU FAU Mackenzie; São Paulo; Brasil. E-mail: wilsonflorio@gmail.com

\section{RESUMO}

Este artigo apresenta uma investigação sobre a efetividade de metodologias de modalidade prescritiva, dedicadas a assegurar o conforto ambiental lumínico em edifícios residenciais projetados e construídos na capital paulista durante a vigência do Código de Obras e Edificações da Cidade de São Paulo (COESP), promulgado em 1992 e revogado em 2017. Por meio de processos de modelagem digital e simulação paramétrica, serão analisados os padrões de iluminância associados a iluminação natural registrados em unidades habitacionais, utilizando como base para a obtenção dos resultados, os parâmetros determinados pela NBR 15575 - Desempenho das edificações habitacionais. As diretrizes de caráter prescritivo, voltadas a assegurar condições minimante satisfatórias de iluminação e aeração, impostas pelas legislações vigentes no período de projeto e execução da produção arquitetônica analisada, exerciam grande impacto nas soluções volumétricas, nas estratégias de implantação dos edifícios e, por consequência, na configuração de extensas áreas urbanas da cidade de São Paulo. A análise da efetividade destes dispositivos legais, por meio do emprego de tecnologias digitais dedicadas à simulação e análise do desempenho lumínico de edifícios residenciais verticais, tem como meta o fornecimento de um conjunto de sistematizado de informações que poderá auxiliar na proposição de futuras investigações sobre temas ligados às metodologias de projeto arquitetônico, conforto ambiental, eficiência energética e configuração de contextos urbanos. PALAVRAS-CHAVE: análise de desempenho; simulação paramétrica; luz natural.

\section{RESUMEN}

Este artículo presenta una investigación sobre la eficacia de las metodologías de modalidad prescriptiva, dedicadas a asegurar el confort ambiental luminoso en los edificios residenciales diseñados y construidos en la capital de São Paulo durante la vigencia del Código de Construcción y Edificación de la Ciudad de São Paulo (COESP), promulgado en 1992 y revocado en 2017. Por medio de procesos de modelación digital y simulación paramétrica, se analizará los patrones de iluminación asociados a la luz natural registrados en las unidades habitacionales, utilizando como base para la obtención de los resultados los parámetros determinados por la NBR 15575 - Desempeño de los Edificios Habitacionales. Las directrices prescriptivas, destinadas a asegurar condiciones mínimas satisfactorias de iluminación y aireación, impuestas por la legislación vigente durante el período de diseño y ejecución de la producción arquitectónica analizada, tuvieron un gran impacto en las soluciones volumétricas, en las estrategias de implantación de los edificios y, en consecuencia, en la configuración de extensas áreas urbanas de la ciudad de São Paulo. El análisis de la eficacia de estos dispositivos legales, mediante el uso de tecnologías digitales dedicadas a la simulación y el análisis del rendimiento lumínico de los edificios residenciales verticales, tiene por objeto proporcionar un conjunto de información sistematizada que pueda ayudar a proponer futuras investigaciones sobre cuestiones relacionadas con las metodologías de diseño arquitectónico, el confort ambiental, la eficiencia energética y la configuración de los contextos urbanos.

PALABRAS CLAVE: análisis de rendimiento; simulación paramétrica; luz natural.

\section{ABSTRACT}

This article presents an investigation on the effectiveness of prescriptive methodologies, dedicated to ensuring luminous environmental comfort in residential buildings designed and built in the capital city of São Paulo during the term of the São Paulo City Building and Construction Code (COESP), promulgated in 1992 and revoked in 2017. By means of digital modeling and parametric simulation processes, the lighting patterns associated with natural lighting recorded in residential units will be analyzed, using the parameters determined by NBR 15575 - Performance of Residential Buildings as the basis for obtaining the results. The prescriptive guidelines, aimed at ensuring satisfactory minimum lighting and aeration conditions, imposed by the legislation in force during the period of design and execution of the architectural production analyzed, had a great impact on the volumetric solutions, on the strategies of building implantation and, consequently, on the configuration of extensive urban areas of the city of São Paulo. The analysis of the effectiveness of these legal devices, through the use of digital technologies dedicated to the 
simulation and analysis of the lighting performance of vertical residential buildings, aims to provide a set of systematized information that may help in the proposition of future investigations on themes related to architectural design methodologies, environmental comfort, energy efficiency and the configuration of urban contexts. KEY WORDS: performance analysis; parametric simulation; natural light.

Recebido em: $17 / 12 / 2020$ Aceito em: 10/08/2021

\section{INTRODUÇÃO}

Segundo Carlo e Lamberts (2010), a validação da eficiência de um determinado sistema a partir da aplicação de métodos prescritivos de avaliação se dá pela observação de uma série de parâmetros predefinidos ou calculados a partir de fórmulas de caráter genérico. A respeito do desempenho lumínico das edificações, a aferição de eficiência através de metodologias cuja aplicação se baseia em um conjunto de regras gerais previamente estabelecidas tende a apresentar resultados de limitada amplitude, por serem incapazes de abranger todas as variáveis que influenciam na qualidade da iluminação natural incidente.

Tal problemática, no entanto, pode ser abordada através da implementação de metodologias de análise de desempenho associadas à utilização de modelagem e simulação paramétrica. Quando utilizados como instrumentos de análise de desempenho, estes recursos são capazes de considerar grande volume de variáveis (como fatores geoclimáticos locais, relevo, disposição do entorno e características físicas de materiais e componentes construtivos - a exemplo de opacidade, refletância etc.), estabelecendo uma dinâmica que se opõe aos processos convencionais de projeto e de análises de desempenho, geralmente balizados por diretrizes legais de caráter prescritivo em conjunto com heurísticas e pressupostos derivados da experiência profissional (HAYMAKER, et al., 2018, p. 158).

$\mathrm{Na}$ cidade de São Paulo, desde a promulgação das primeiras legislações dedicadas a orientar o desenvolvimento de projetos arquitetônicos e a execução de obras de construção civil (com destaque para as edificações de uso residencial), se fazem presentes diversas diretrizes legais de caráter prescritivo direcionadas à garantia de condições minimamente satisfatórias de acesso à iluminação natural nos ambientes destinados ao convívio social, trabalho e repouso.

A Lei $n^{\circ}$ 2332/20, que estabelecia o "padrão municipal" para as construções particulares no município, exigia que edifícios construídos antes de 1920 (ano de promulgação da Lei) apresentassem no mínimo uma hora diária de insolação durante o solstício de inverno. Após esta data, as novas construções deveriam receber, no mínimo, três horas diárias de insolação (FREITAS JR., 2008). Em 1929 entra em vigor a Lei ${ }^{\circ}$ 34297/29 (Código de obras Artur Saboya), que além de manter esta normativa, determina com base na área de piso dos ambientes, o dimensionamento mínimo de aberturas voltadas a iluminação e ventilação.

O código de obras Artur Saboya instituiu, ainda, parâmetros referentes ao alinhamento e gabarito das edificações, cujos limites estavam associados a largura das vias onde os edifícios se localizavam. Em 1934, alguns pontos da Lei foram revisados, permitindo um aumento significativo na altura das edificações, desde que fosse respeitado um escalonamento dos pavimentos superiores, configurados também a partir da largura da via. Esta metodologia se manteve vigente até 1975, quando um novo código de obras foi publicado, devido a necessidade de adequar os parâmetros projetuais e a prática construtiva às novas diretrizes impostas pela lei de uso e ocupação do solo (LPUOS), promulgada no ano de 1972.

Além de manter o dimensionamento mínimo de aberturas para ventilação e iluminação em função da área de piso dos ambientes, com o objetivo de garantir condições mínimas de aeração, insolação e iluminação natural, o Código de Edificações de 1975 instituiu a aplicação de faixas não edificadas ao redor do perímetro dos edifícios verticais, cujas dimensões eram definidas a partir do gabarito adotado. Desde a promulgação deste Código, o gabarito dos edifícios deixou de se vincular a largura da via, passando a ser definido em função da área do lote, a partir da observância da taxa de ocupação e coeficiente de aproveitamento, determinados pela LPUOS de 1972.

Em 1992 foi publicado o Código de Obras e Edificações - COESP (Lei no 11.228/1992), revogando desta maneira, o Código de Edificações de 1975, "com o objetivo de ser compreendido por toda a comunidade de técnicos e, desta vez, separando completamente as questões construtivas (edilícias) das questões de zoneamento (urbanísticas)" (MORAES, 2013, p. 96). Sobre os dispositivos relativos à aeração, à insolação e à iluminação natural, ocorre a substituição das Faixas Livres, instituídas no código anterior, pela "Faixa A" (aeração) e pelo "Espaço I" (insolação).

Para os edifícios verticais de uso residencial, a obediência a estes parâmetros era demonstrada por meio da configuração de projeções em forma de arcos e semicírculos, que deveriam ser acondicionados entre as faces onde se situavam as aberturas dos ambientes de longa permanência (salas e dormitórios) e os limites do lote. Os raios destas projeções eram definidos por fórmulas matemáticas, configuradas a partir de 
parâmetros relacionados à altura e quantidade de pavimentos da edificação em projeto. As dimensões mínimas das aberturas, no entanto, continuavam a ser definidas pelo mesmo método utilizado nas legislações anteriores (Tabela 01).

Tabela 01: Dimensionamento de aberturas

\begin{tabular}{|c|c|c|}
\hline \multicolumn{3}{|c|}{$\begin{array}{l}\text { Dimensionamento mínimo de ambientes e aberturas } \\
\text { código de obras e edificações da cidade de São Paulo - } 1992\end{array}$} \\
\hline Ambientes & Dimensionamento mínimo & $\begin{array}{l}\text { Aberturas } \\
\text { (\% área ambiente) }\end{array}$ \\
\hline Repouso/Estar/Estudo: & $\begin{array}{l}\text { Pé direto mín.: 2,50 m } \\
\text { Área mín.: } 5,00 \mathrm{~m}^{2} \\
\text { Conter círculo }(\varnothing): 2,00\end{array}$ & $\begin{array}{l}\text { Insolação: } 15 \%\left(\min .0,6 m^{2}\right) \\
\text { Ventilação: } 75 \%\left(\min .0,3 m^{2}\right)\end{array}$ \\
\hline Cozinha/Copa/Lavanderia: & $\begin{array}{l}\text { Pé direto mín.: 2,50 m } \\
\text { Área mín.: - } \\
\text { Conter círculo }(\varnothing): 1,20\end{array}$ & $\begin{array}{l}\text { Insolação: - } \\
\text { Ventilação: } 5 \%\left(\min .0,3 m^{2}\right)\end{array}$ \\
\hline
\end{tabular}

Em decorrência da instituição do Plano Diretor Estratégico do Município de São Paulo (Lei no 16.050, de 31 de julho de 2014) e da revisão da LPUOS (Lei no 16.402, de 22 de março de 2016), foi promulgado um novo Código de Obras Edificações (Lei no 16.642, de 9 de maio de 2017), que tem como característica marcante, a supressão de uma série de dispositivos normativos de natureza prescritiva, sobretudo aqueles destinados a orientar estratégias projetuais relacionadas a aeração e insolação das edificações.

Apesar de manter a obrigatoriedade de recuos entre edificações e os limites dos lotes, o novo código deixou de indicar parâmetros mínimos quanto ao dimensionamento de aberturas, bem como a necessidade de faixas e espaços livres destinados a aeração e insolação. Desde então, o dimensionamento das aberturas, visando condições minimamente satisfatórias de aeração e iluminação natural, assim como a qualidade e efetividade desta iluminação, passaram a ser orientadas pelas normas técnicas de desempenho, como a NBR 15575 - Desempenho das Edificações Residenciais, ou por leis de caráter mais específico, como o Código Sanitário do Estado de São Paulo (Decreto n 12.342, de 27 de setembro de 1978).

\section{OBJETIVOS E JUSTIFICATIVA}

O objetivo dos processos de simulação e análise (integrantes de uma pesquisa de caráter mais abrangente) apresentados neste artigo é verificar a eficácia de metodologias propostas pelo COESP vigente durante o período compreendido entre os anos de 1992 e 2017, voltadas a garantir condições satisfatórias de insolação e iluminação natural em edifícios residenciais.

Como estas diretrizes exerciam grande impacto tanto nas soluções volumétricas quanto nas estratégias de implantação dos edifícios em relação aos limites do lote e às vias públicas, os resultados da aplicação deste conjunto normativo acabou por influenciar de maneira direta na configuração de extensas áreas urbanas. Isso se justifica pois, segundo dados sobre a produção de empreendimentos residenciais na região metropolitana de São Paulo reunidos pela Empresa Brasileira de Estudos de Patrimônio (EMBRAESP), a produção de edifícios residenciais na capital paulista entre 1992 e 2017 (período de vigência do COESP de 1992) foi de 9.827 exemplares (Gráfico 01).

Gráfico 01: empreendimentos residenciais verticais - cidade de São Paulo - junho/1992 - maio/2017

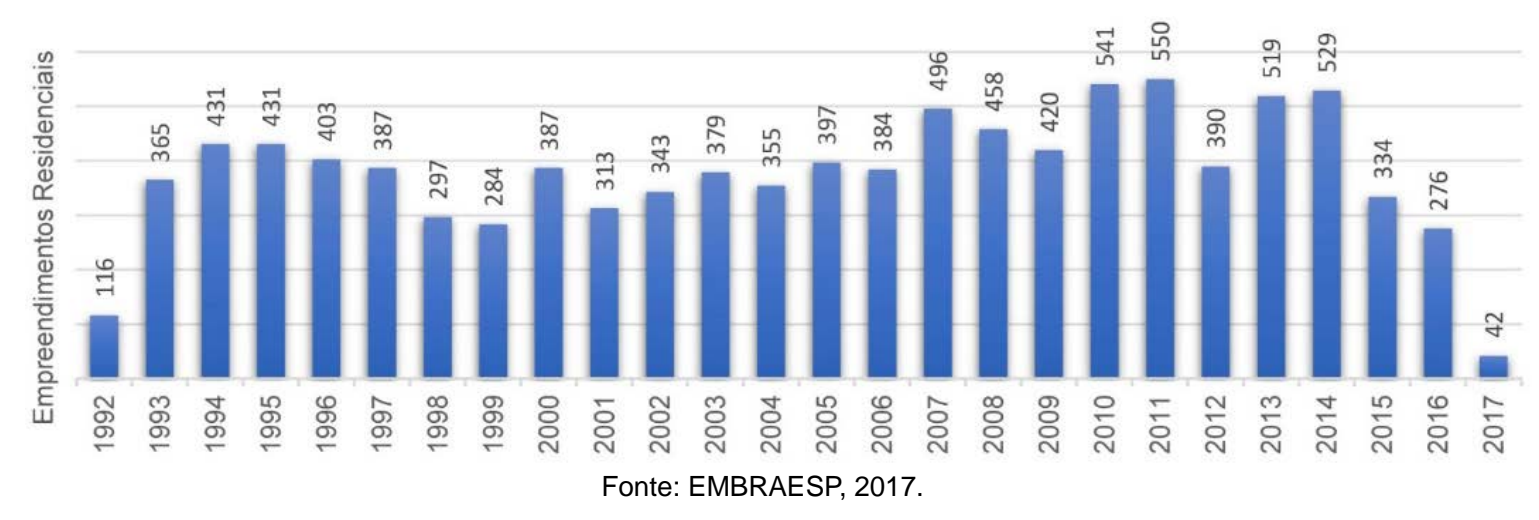


Desta forma, uma pesquisa baseada em tecnologias digitais dedicadas à simulação e análise de desempenho, com foco no conforto ambiental lumínico de edifícios residenciais verticais, pode fornecer subsídios para futuras investigações e contribuir para a discussão de temas relacionados às metodologias de projeto arquitetônico e nas suas relações com a configuração de contextos urbanos.

\section{REFERENCIAL TEÓRICO}

O referencial teórico é constituído primordialmente por trabalhos acadêmicos anteriores, que abordam temas relacionados ao conforto ambiental, eficiência energética, modelagem tridimensional, simulação paramétrica e metodologias de projeto voltadas a produção de edifícios verticais, bem como àqueles dedicados a discutir as consequências, em termos de constituição da morfologia urbana, da formulação e aplicação das diversas legislações urbanas e construtivas que incidem, ou incidiram, sobre o ordenamento espacial das cidades brasileiras.

Destacam-se como referências, as pesquisas de Figueiredo (2011), que analisa a eficiência dos vedos translúcidos e transparentes em edifícios das cidades de São Paulo, Berlim e Frankfurt am Main, produzidos durante as últimas décadas do século XX e primeira década do século XXI, através de medições in loco dos padrões de iluminância, processados posteriormente em softwares dedicados a simulação e análise lumínica; e de Gonçalves et al. (2018), que desenvolveram estudos sobre o desempenho bioclimático de edifícios representativos da arquitetura moderna brasileira, como o COPAN.

\section{OBJETO DE ESTUDO}

O objeto de estudo da pesquisa em desenvolvimento (BOSCARDIN, 2021) considera variadas tipologias arquitetônicas de uso residencial vertical. Neste artigo é apresentado um conjunto de simulações e análises executadas a partir da modelagem tridimensional de um empreendimento residencial de torre única (Figuras 01 e 02) que abriga seis unidades habitacionais por pavimento, sendo caracterizado conforme as indicações a seguir:

- PROJETO EM ANÁLISE: Energy Brooklin

- ANO DE CONCLUSÃO do projeto: 2017

- ENDEREÇO: Rua Jacerú, 346 - Vila Gertrudes, São Paulo/SP

- PROJETO ARQUITETÔNICO: Königsberger Vannucchi Arquitetos Associados

- NÚMERO DE PAVIMENTOS TIPO: 28 (26 tipos+duplex)

- COEFICIENTE DE APROVEITAMENTO: 4

- TAXA DE OCUPAÇÃO: $50 \%$

Figura 01: edifício Energy Brooklin

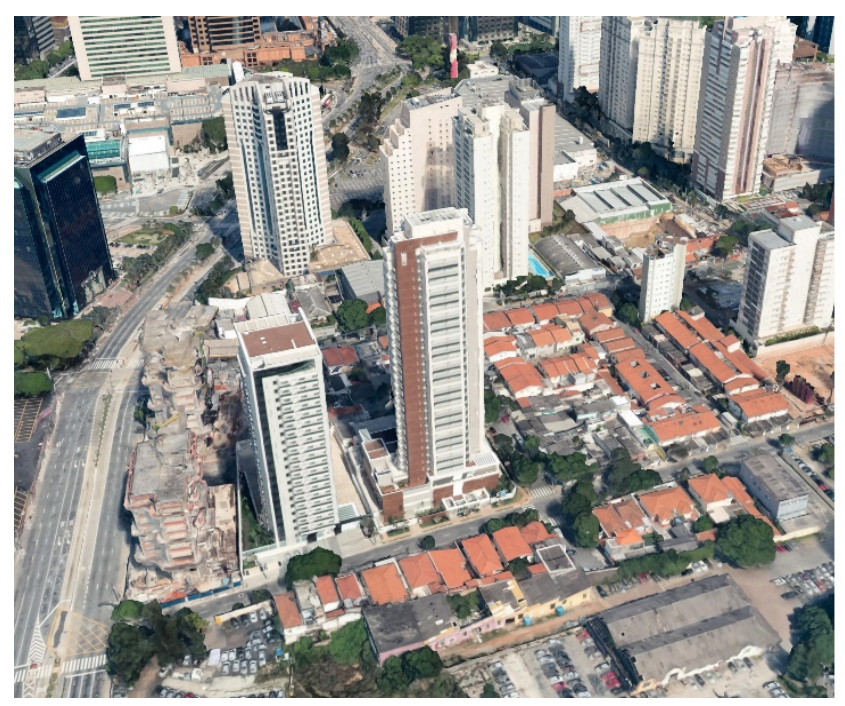

Fonte: Google Earth (2020)
Figura 02: Localização

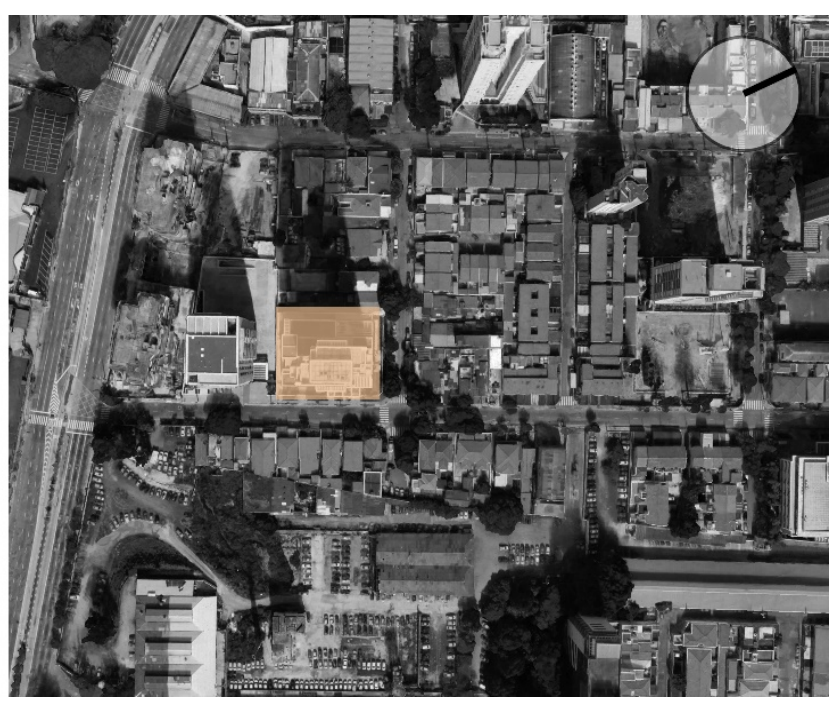

Fonte: Google Earth, editado por Boscardin, 2021. 
A respeito da resolução da planta tipo, proporção entre áreas de ambientes e aberturas e número de pavimentos ${ }^{1}$, o edifício apresenta características projetuais típicas dos empreendimentos residenciais produzidos durante o período abordado. A sua implantação, em um lote localizado em área urbana marcada pela ocorrência de gabaritos com diferentes alturas (denotando um processo de transição, onde as residências de um ou dois pavimentos tendem a ser substituídas por edifícios verticais) também representa uma condição comum à época.

\section{PROCEDIMENTOS METODOLÓGICOS}

\section{Fluxo de trabalho}

Os processos de simulação desenvolvidos na pesquisa (BOSCARDIN, 2021) têm por objetivo possibilitar uma série de análises sobre o desempenho lumínico, especificamente a respeito da luz natural, através do exame dos padrões de iluminância presentes em determinados ambientes internos das unidades habitacionais. Estes procedimentos foram realizados de acordo com o seguinte fluxo de trabalho (Figura 03):

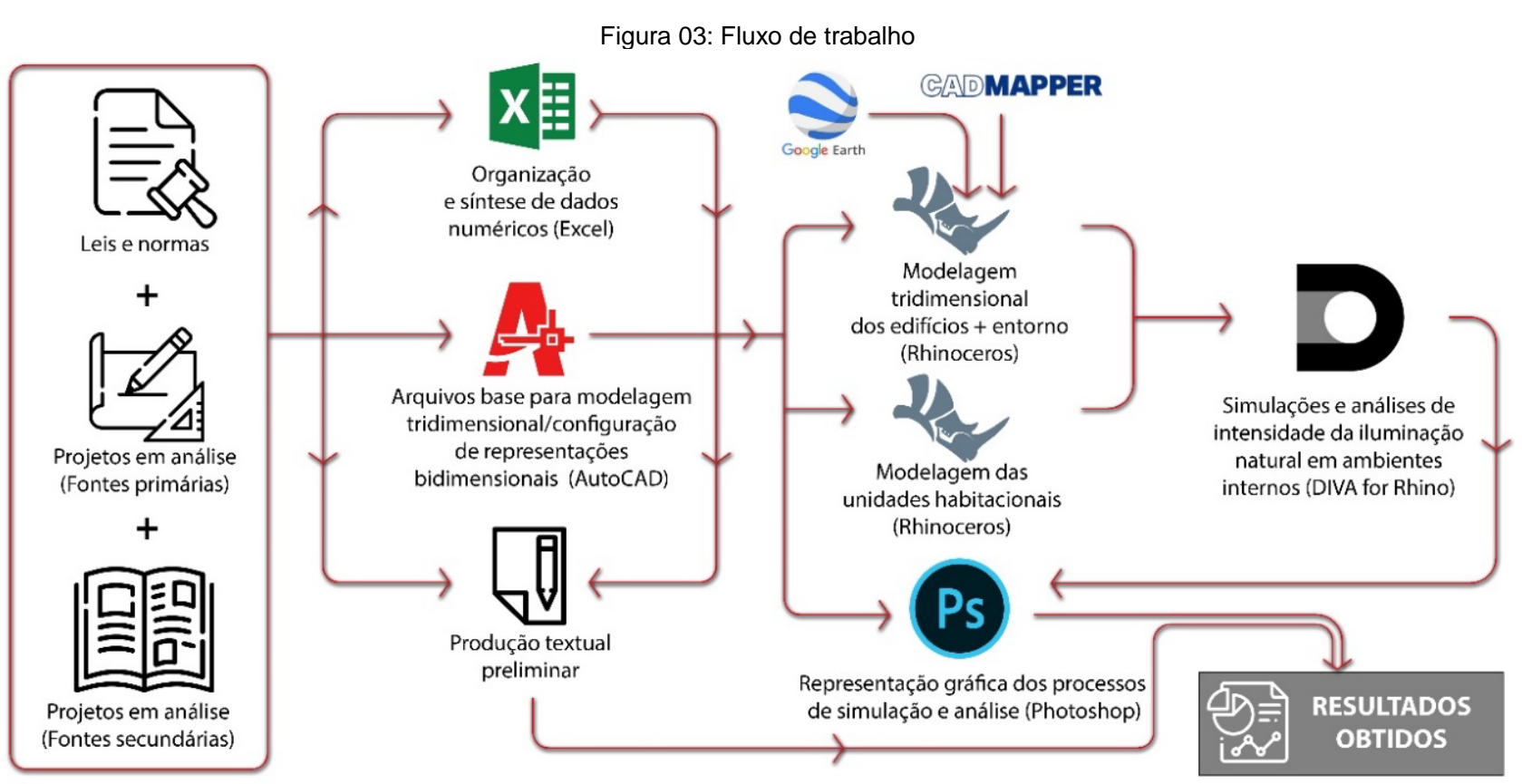

Fonte: Boscardin (2021).

Os modelos tridimensionais apresentados neste artigo foram desenvolvidos através do software Rhinoceros, com a geometria do edifício em análise baseada em fontes primárias de pesquisa (arquivos de projeto originais). As informações referentes ao entorno foram obtidas através das plataformas virtuais Google Earth e CadMapper. As representações gráficas bidimensionais (implantação, demonstrativo de "Faixa A" e "Espaço I" e plantas das unidades habitacionais) foram desenhadas no software AutoCAD, a partir de fontes primárias e em entendimento com as legislações pertinentes.

\section{Ferramentas de simulação empregadas}

As simulações de desempenho lumínico constantes neste artigo foram geradas a partir do conjunto de dados contidos em arquivos do tipo *.EPW (Energy Plus Weather Data), que armazenam informações relacionadas à temperatura, umidade relativa do ar, velocidade e direção dos ventos, nebulosidade da atmosfera, entre outras, para diversas regiões do globo. As simulações utilizaram 0 arquivo BRA_SP_Sao.Paulo-Congonhas.AP.837800_TMYX.2003-2017.epw, fornecido gratuitamente para download pelo Laboratório de Eficiência Energética em Edificações (labEEE) da Universidade Federal de Santa Catarina.

As análises da intensidade de iluminação natural no interior das unidades habitacionais foram executadas pela operação do plugin DIVA-for-Rhino, vinculado ao software de modelagem tridimensional Rhinoceros, 
capaz de desenvolver simulações de desempenho lumínico e energético para edifícios e contextos urbanos. O plugin foi inicialmente desenvolvido na Graduate School of Design da Universidade de Harvard, e atualmente é distribuído pela Solemma LLC. O DIVA-for-Rhino oferece dois conjuntos de ferramentas: enquanto um deles funciona diretamente sobre a interface do Rhinoceros, o outro se integra ao plugin Grasshopper (DIVA4), o que possibilita a criação de algoritmos personalizados e de maior complexidade.

O método de seleção das unidades habitacionais (UHs) alvo das simulações dos padrões de iluminância interna considerou o posicionamento destas em relação à trajetória solar: duas UHs situadas no pavimento mais alto, com condições opostas no que diz respeito ao posicionamento de suas aberturas, com a primeira (UH01) recebendo a maior parte da luz natural por insolação direta, enquanto a segunda (UH02) sendo majoritariamente iluminada por processo de difusão atmosférica ou reflexão, complementadas por uma unidade situada no pavimento tipo mais baixo (UH03), com orientação semelhante à UH02.

\section{Parâmetros de Mensuração}

Os parâmetros de avaliação adotados se baseiam nos apresentados pela NBR 15575 - Desempenho de edificações habitacionais (Tabelas 02), que determina os valores mínimos de iluminância, bem como as datas, horários e demais procedimentos que devem ser considerados nos processos de simulação.

Tabela 02: NBR 15575 - níveis de iluminamento natural

\begin{tabular}{|c|c|c|c|}
\hline \multicolumn{4}{|c|}{ NBR 15575 - níveis de iluminamento natural } \\
\hline \multirow{2}{*}{ Dependência } & \multicolumn{3}{|c|}{$\begin{array}{l}\text { Iluminamento geral para os níveis de desempenho } \\
\text { (Lux) }\end{array}$} \\
\hline & Mínimo & Intermediário & Superior \\
\hline $\begin{array}{l}\text { Sala de Estar; dormitório; copa/cozinha; Área } \\
\text { de Serviço }\end{array}$ & $\geq 60$ & $\geq 90$ & $\geq 120$ \\
\hline $\begin{array}{l}\text { Banheiro; corredor ou escada interna à } \\
\text { unidade; corredor e escadarias de uso comum } \\
\text { (prédio); garagens e estacionamentos }\end{array}$ & não exigido & $\geq 30$ & $\geq 45$ \\
\hline \multicolumn{4}{|c|}{$\begin{array}{l}\text { Localização e orientação solar: Além da orientação solar, considerar a latitude e a longitude do local da obra, bem } \\
\text { como os diferentes pavimentos e as diferentes posições dos apartamentos nos andares. } \\
\text { Datas e horários das simulações: dias } 23 \text { de abril e } 23 \text { de outubro, períodos da manhã (9:30h) e da tarde (15:30h). } \\
\text { Condição do céu: supor dias com nebulosidade média (índice de nuvens } 50 \% \text { ). } \\
\text { Parametros espaciais de simulação: ponto de medição principal no centro dos ambientes, na altura de 0,75m } \\
\text { acima do nível do piso. Obstruços pontuais: considerar janelas, cortinas e portas internas abertas. Obstruções } \\
\text { externas: considerar os eventuais sombreamentos resultantes de edificações vizinhas, taludes, muros e outros } \\
\text { possíveis anteparos, desde que se conheçam o local e as condições de implantação da obra². }\end{array}$} \\
\hline
\end{tabular}

Fonte: NBR 15575 (2013)

A NBR 15575, porém, não define um limite máximo para iluminâncias. Neste estudo, no entanto, foi adotado com base no sistema de medição UDI (Useful Daylight Illuminances), o limite máximo de 2000 lux, que se ultrapassado pode contribuir para uma situação de desconforto térmico e/ou visual. Este valor também é utilizado como referência pela NBR 8995 (lluminação de ambientes de trabalho) para determinar a iluminância limite a ser alcançada em ambientes que se destinam a execução de tarefas que exigem alta acuidade visual. Em síntese, valores abaixo do limite mínimo (60 lux) indicam baixa iluminação e a necessidade de luz artificial, enquanto valores acima do máximo (2000 lux) se traduzem em excesso de brilho e ganhos térmicos indesejáveis (HOPPE; ALVAREZ; LARANJA, 2015).

As análises de iluminância em ambientes internos se basearam nos seguintes parâmetros de avaliação:

- Relação percentual das áreas das aberturas em relação às áreas de piso dos ambientes onde estas se encontram.

- Iluminância média do ambiente (em lux).

- Percentual da área de piso do ambiente com iluminâncias compreendidas entre os 60 e 2000 lux.

- Percentual da área de piso do ambiente com iluminâncias abaixo dos 60 lux.

- Percentual da área de piso do ambiente com iluminâncias acima dos 2000 lux. 
Apesar do critério de análise proposto pela NBR 15575 considerar apenas a intensidade de iluminância registrada no centro dos compartimentos, a visualização dos mapas de iluminância relativos à área total dos ambientes simulados favorece o desenvolvimento de análises mais acuradas sobre a distribuição da luz natural e suas possíveis relações com o formato destes, bem como a partir da posição e dimensionamento das aberturas.

\section{RESULTADOS OBTIDOS}

Projetado ainda sob a vigência do COESP de 1992, a posição do edifício no lote e o arranjo de planta dos pavimentos tipo foram configurados de modo que fosse possível a acomodação das representações da "Faixa A" (aeração, em azul) e dos "Espaços I" (insolação, em vermelho), cujas dimensões se relacionam diretamente com o gabarito da edificação (Figura 04).

Figura 04: implantação/demonstrativo de Faixa A e Espaço I

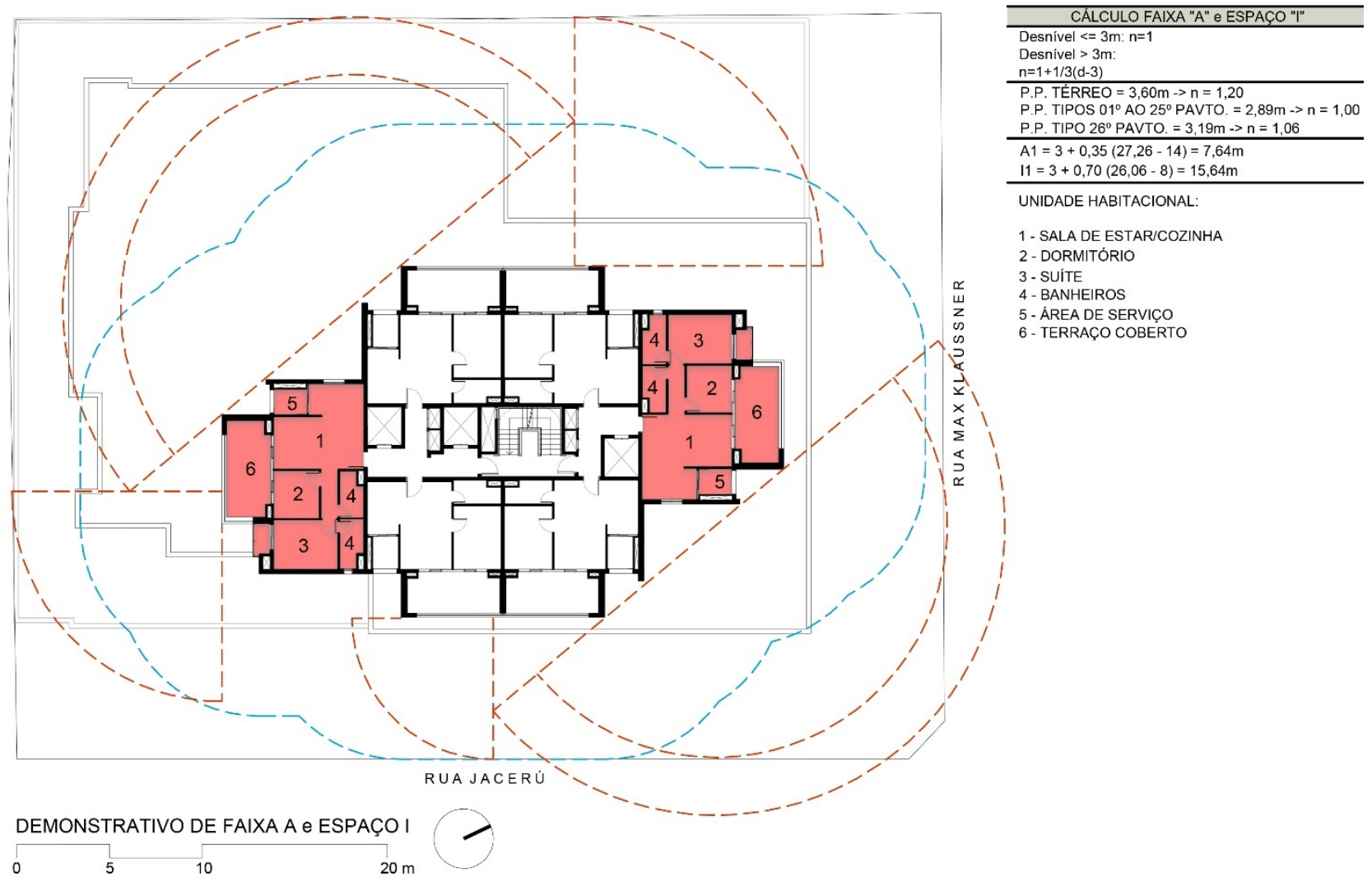

Fonte: Boscardin (2021).

\section{Simulações de iluminâncias em ambientes internos}

Os processos de simulação das condições de acesso à iluminação natural das unidades habitacionais selecionadas (Figura 05) resultaram na produção dos seguintes diagramas das Figuras 06 a 11. 
Figura 05: estudo volumétrico e localização das unidades habitacionais em análise.

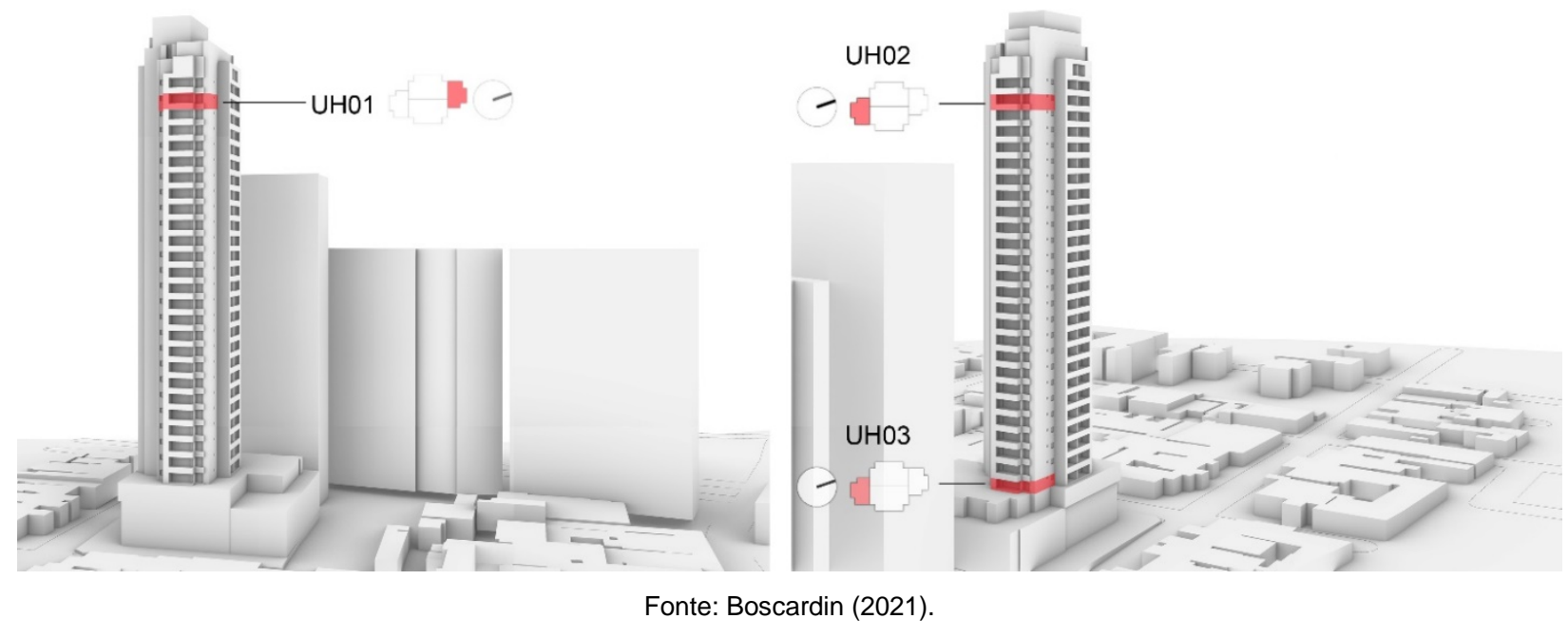

Figura 06: análises de iluminâncias - UH 01, localizada no $26^{\circ}$ pavimento, em 23 de abril - 9:30 /15:30 H.

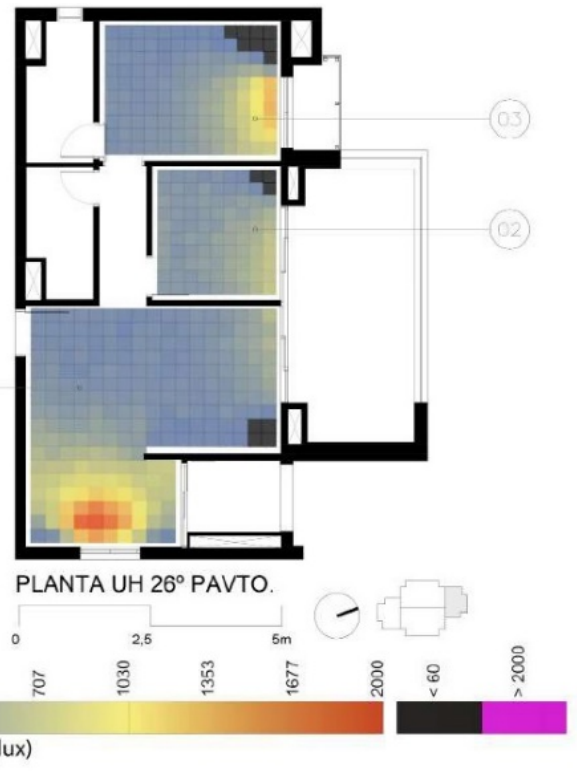

lluminância (lux)

\begin{tabular}{|c|c|c|c|c|c|}
\hline \multicolumn{6}{|c|}{ ANÁLISE DE ILUMINÂNCIAS - LUZ NATURAL AMBIENTES INTERNOS } \\
\hline \multicolumn{6}{|c|}{ data: 23/abr. horário: 9:30 } \\
\hline Ambiente & $\begin{array}{l}\text { Relaçâo área } \\
\text { piso/aberturas }\end{array}$ & Ilum. média & $\begin{array}{l}\text { llum. entre } \\
60 \text { e } 2000 \mathrm{~lx}\end{array}$ & $\begin{array}{l}\operatorname{llum}_{<60 \mid x} \\
<\end{array}$ & $\begin{aligned} & \text { llum. } \\
> & 2000 \mathrm{~lx}\end{aligned}$ \\
\hline 01 & $27,01 \%$ & $381,12 \mid x$ & $98,3 \%$ & $1,7 \%$ & - \\
\hline 02 & $60,48 \%$ & $307,11 \mid x$ & $96,7 \%$ & $3,3 \%$ & - \\
\hline 03 & $30,88 \%$ & 308,86 Ix & $93,8 \%$ & $6,2 \%$ & - \\
\hline
\end{tabular}

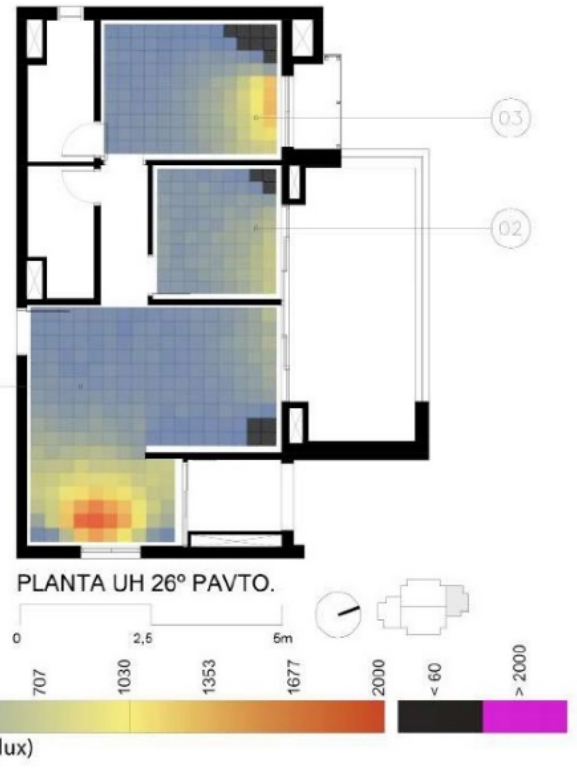

ANALISE DE ILUMINÁNCIAS - LUZ NATURAL AMBIENTES INTERNOS

\begin{tabular}{c|c|c|c|c|c}
\hline \multicolumn{7}{c}{ data: 23/abr. horário: 15:30 } \\
\hline Ambiente & $\begin{array}{c}\text { Relação área } \\
\text { piso/aberturas }\end{array}$ & Ilum. média & $\begin{array}{c}\text { Ilum. entre } \\
60 \text { e 2000 Ix }\end{array}$ & $\begin{array}{c}\text { Ilum. } \\
<60 \mathrm{Ix}\end{array}$ & $\begin{array}{c}\text { Ilum. } \\
>2000 \mathrm{Ix}\end{array}$ \\
\hline 01 & $27,01 \%$ & $163,64 \mathrm{~lx}$ & $87,8 \%$ & $12,2 \%$ & - \\
\hline 02 & $60,48 \%$ & $178,49 \mathrm{~lx}$ & $92,2 \%$ & $7,8 \%$ & - \\
\hline 03 & $30,88 \%$ & $197,42 \mathrm{~lx}$ & $77,7 \%$ & $22,3 \%$ & - \\
\hline
\end{tabular}

Fonte: Boscardin (2021). 
Figura 07: análises de iluminâncias - UH 01, localizada no $26^{\circ}$ pavimento, em 23 de outubro - 9:30 /15:30 H.

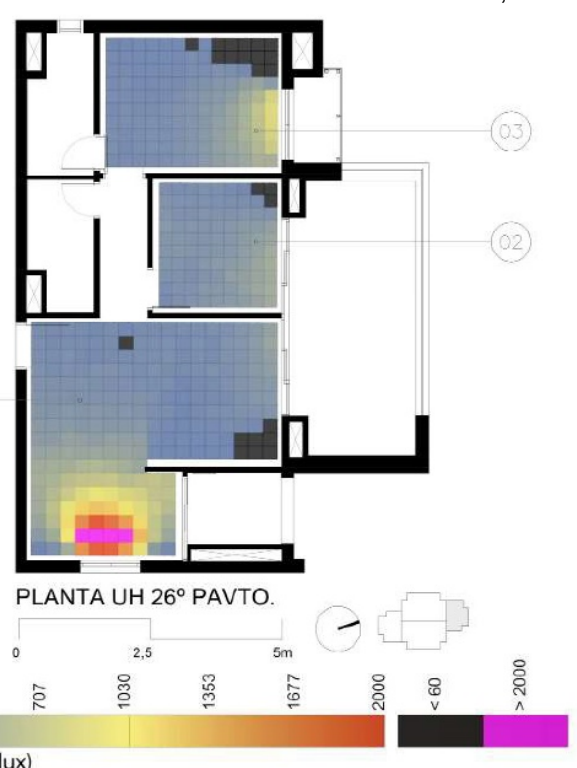

Iluminância (lux)

\begin{tabular}{|c|c|c|c|c|c|}
\hline \multicolumn{6}{|c|}{ ANÁLISE DE ILUMINÅNCIAS - LUZ NATURAL AMBIENTES INTERNOS } \\
\hline \multicolumn{6}{|c|}{ data: 23 /out. horário: $9: 30$} \\
\hline Ambiente & $\begin{array}{l}\text { Relação área } \\
\text { piso/aberturas }\end{array}$ & Ilum. média & $\begin{array}{l}\text { llum.entre } \\
60 \mathrm{e} 2000 \mathrm{Ix}\end{array}$ & $\underset{<60 \mathrm{~lx}}{\operatorname{llum}}$ & $\begin{aligned} & \text { llum. } \\
> & 2000 \mathrm{~lx}\end{aligned}$ \\
\hline 01 & $27,01 \%$ & $360,54 \mathrm{Ix}$ & $94,9 \%$ & $3,4 \%$ & $1,7 \%$ \\
\hline 02 & $60,48 \%$ & $203,621 x$ & $96,7 \%$ & $3,3 \%$ & - \\
\hline 03 & $30,88 \%$ & $197,77 \mathrm{Ix}$ & $90 \%$ & $10 \%$ & - \\
\hline
\end{tabular}

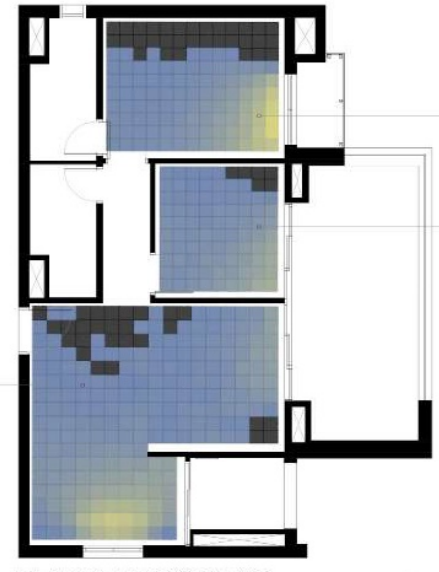

PLANTA UH $26^{\circ}$ PAVTO

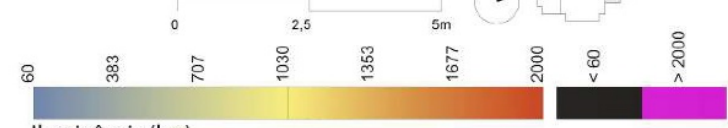

lluminância (lux)

\begin{tabular}{|c|c|c|c|c|c|}
\hline \multicolumn{6}{|c|}{ ANALISE DE ILUMINÅNCIAS - LUZ NATURAL AMBIENTES INTERNOS } \\
\hline \multicolumn{6}{|c|}{ data: 23 /out. horário: $15: 30$} \\
\hline Ambiente & $\begin{array}{c}\text { Relação área } \\
\text { piso/aberturas }\end{array}$ & llum. média & $\begin{array}{l}\text { llum. entre } \\
60 \mathrm{e} 2000 \mathrm{~lx}\end{array}$ & $\begin{array}{l}\text { Ilum. } \\
<60 \text { Ix }\end{array}$ & $\begin{aligned} & \text { llum. } \\
> & 2000 \mathrm{~lx}\end{aligned}$ \\
\hline 01 & $27,01 \%$ & $163,56 \mathrm{~lx}$ & $88,7 \%$ & $11,3 \%$ & - \\
\hline 02 & $60,48 \%$ & $157,74 \mathrm{Ix}$ & $93,3 \%$ & $6,7 \%$ & - \\
\hline 03 & $30,88 \%$ & $167,5 \mathrm{Ix}$ & $75,4 \%$ & $24,6 \%$ & - \\
\hline
\end{tabular}

Fonte: Boscardi (2021).

Figura 08: análises de iluminâncias - UH 02, localizada no $26^{\circ}$ pavimento, em 23 de abril - 9:30 /15:30 H.

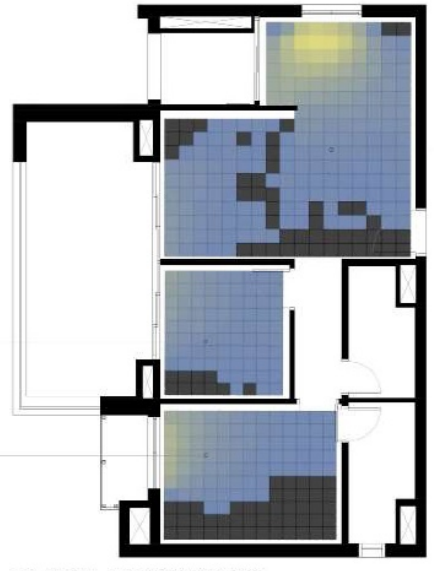

PLANTA UH $26^{\circ}$ PAVTO

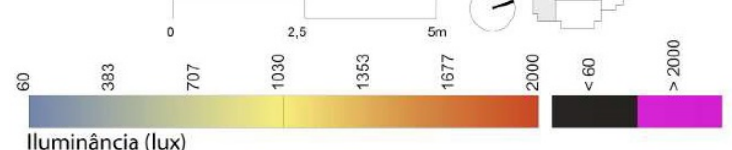

Iluminância (lux)

\begin{tabular}{|c|c|c|c|c|c|}
\hline \multicolumn{6}{|c|}{ ANÁLISE DE ILUMINÅNCIAS-LUZ NATURAL AMBIENTES INTERNOS } \\
\hline \multicolumn{6}{|c|}{ data: $23 / a b r$. horário: 9:30 } \\
\hline Ambiente & $\begin{array}{c}\text { Relação área } \\
\text { piso/aberturas }\end{array}$ & Ilum. média & $\begin{array}{l}\text { llum. entre } \\
60 \text { e } 2000 \mathrm{~lx}\end{array}$ & $\begin{array}{l}\text { Ilum. } \\
<60 \mathrm{~lx}\end{array}$ & $\begin{array}{c}\quad \text { llum. } \\
>2000 \mathrm{Ix}\end{array}$ \\
\hline 01 & $27,01 \%$ & $163,091 \mathrm{x}$ & $80,7 \%$ & $19,3 \%$ & - \\
\hline 02 & $60,48 \%$ & $116,391 \mathrm{x}$ & $88,9 \%$ & $11,1 \%$ & - \\
\hline 03 & $30,88 \%$ & $116,74 \mathrm{Ix}$ & $63,8 \%$ & $36,2 \%$ & - \\
\hline
\end{tabular}

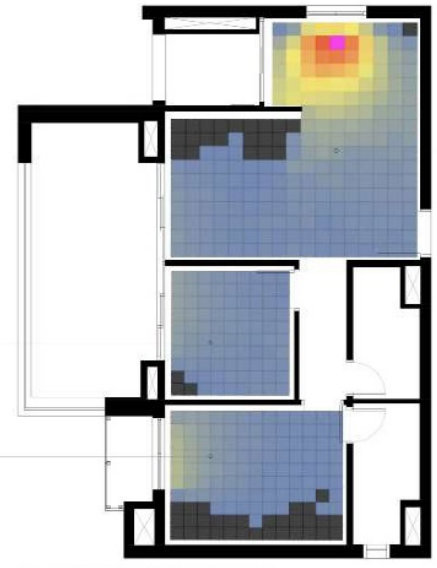

PLANTA UH $26^{\circ}$ PAVTO

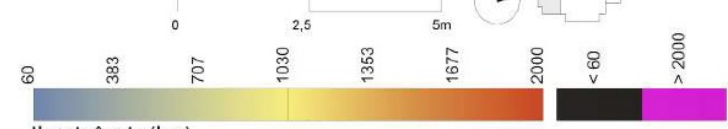

Iluminância (lux)

\begin{tabular}{c|c|c|c|c|c}
\hline \multicolumn{7}{c}{ ANALISE DE ILUMINANCIAS-LUZ NATURAL AMBIENTES INTERNOS } \\
\hline Ambiente & $\begin{array}{c}\text { Relação área } \\
\text { piso/aberturas }\end{array}$ & llum. média & $\begin{array}{c}\text { llum. entre } \\
60 \text { e 2000 Ix }\end{array}$ & $\begin{array}{c}\text { llum. } \\
<60 \mathrm{~lx}\end{array}$ & $\begin{array}{c}\text { llum. } \\
>2000 \mathrm{Ix}\end{array}$ \\
\hline 01 & $27,01 \%$ & $331,29 \mathrm{~lx}$ & $90,4 \%$ & $9,2 \%$ & - \\
\hline 02 & $60,48 \%$ & $139,74 \mathrm{~lx}$ & $96,7 \%$ & $3,3 \%$ & - \\
\hline 03 & $30,88 \%$ & $127,55 \mathrm{~lx}$ & $76,2 \%$ & $23,8 \%$ & - \\
\hline
\end{tabular}

Fonte: Boscardin (2021). 
Figura 09: análises de iluminâncias - UH 02, localizada no $26^{\circ}$ pavimento, em 23 de outubro - 9:30 /15:30 H

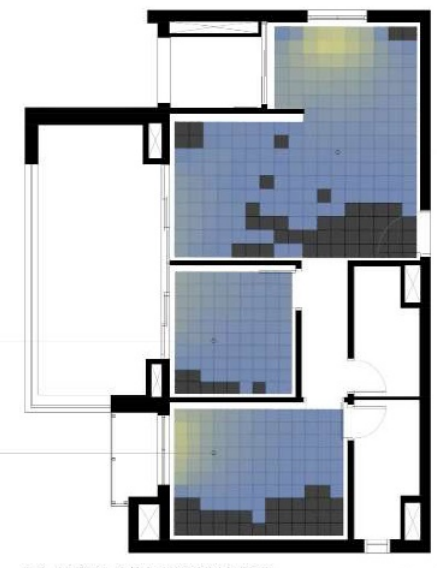

PLANTA UH $26^{\circ}$ PAVTO.

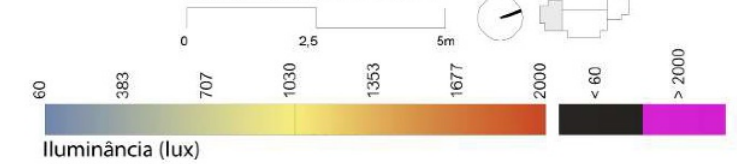

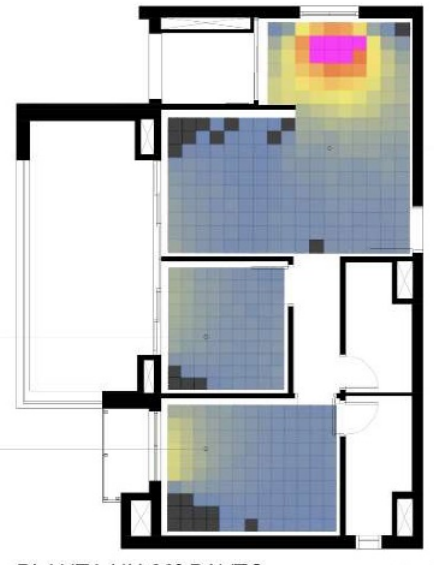

PLANTA UH $26^{\circ}$ PAVTO

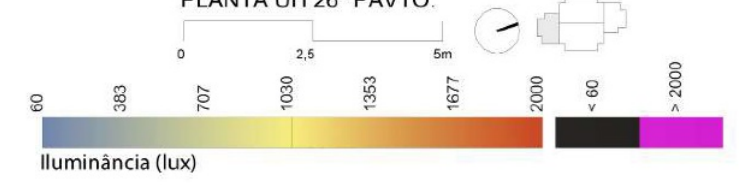

\begin{tabular}{|c|c|c|c|c|c|}
\hline \multicolumn{6}{|c|}{ ANÁLISE DE ILUMINÂNCIAS - LUZ NATURAL AMBIENTES INTERNOS } \\
\hline \multicolumn{6}{|c|}{ data: 23/out. horário: 15:30 } \\
\hline Ambiente & $\begin{array}{l}\text { Relação área } \\
\text { piso/aberturas }\end{array}$ & llum. média & $\begin{array}{l}\text { Ilum. entre } \\
60 \text { e } 2000 \text { Ix }\end{array}$ & $\underset{<60 \text { Ix }}{\operatorname{llum} \text {. }}$ & $\begin{array}{l}\text { Ilum. } \\
>2000 \mathrm{~lx}\end{array}$ \\
\hline 01 & $27,01 \%$ & $418,47 \mathrm{Ix}$ & $92,1 \%$ & $5 \%$ & $2,9 \%$ \\
\hline 02 & $60,48 \%$ & $209,32 \mathrm{Ix}$ & $95,6 \%$ & $4,4 \%$ & - \\
\hline 03 & $30,88 \%$ & $195,74 \mathrm{Ix}$ & $91,5 \%$ & $8,5 \%$ & - \\
\hline
\end{tabular}

Fonte: Boscardin (2021).

Figura 10: análises de iluminâncias - UH 03, localizada no $1^{\circ}$ pavimento, em 23 de abril - 9:30 /15:30 H.

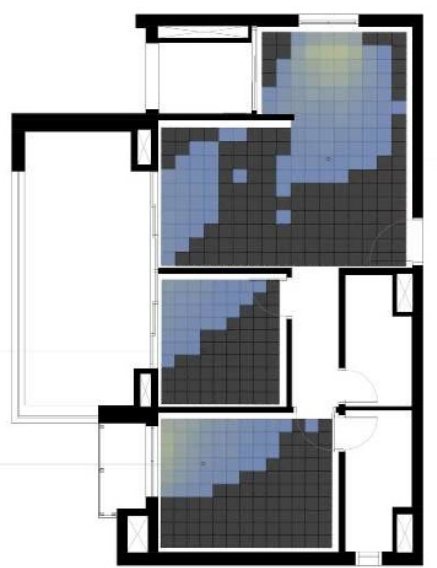

PLANTA UH $1^{\circ}$ PAVTO.

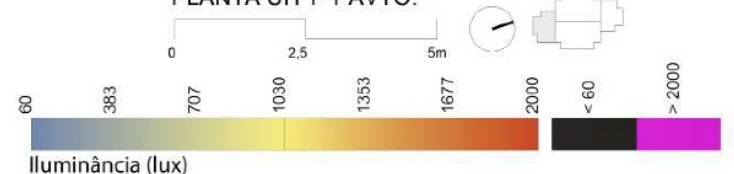

Iluminância (lux)

\begin{tabular}{|c|c|c|c|c|c|}
\hline \multicolumn{6}{|c|}{ ANÁLISE DE ILUMINÂNCIAS - LUZ NATURAL AMBIENTES INTERNOS } \\
\hline \multicolumn{6}{|c|}{ data: 23/abr. horário: 9:30 } \\
\hline Ambiente & $\begin{array}{c}\text { Relação área } \\
\text { piso/aberturas }\end{array}$ & Ilum. média & $\begin{array}{l}\text { Ilum, entre } \\
60 \mathrm{e} 2000 \mathrm{Ix}\end{array}$ & $\begin{array}{l}\text { Ilum. } \\
<60 \text { Ix }\end{array}$ & $\begin{aligned} & \text { Ilum. } \\
&> 2000 \mathrm{~lx} \\
&\end{aligned}$ \\
\hline 01 & $27,01 \%$ & $92,26 \mathrm{Ix}$ & $47,1 \%$ & $52,9 \%$ & - \\
\hline 02 & $60,48 \%$ & $58,56 \mathrm{Ix}$ & $36,7 \%$ & $63,3 \%$ & - \\
\hline 03 & $30,88 \%$ & $81,58 \mathrm{Ix}$ & $36,2 \%$ & $63,8 \%$ & - \\
\hline
\end{tabular}

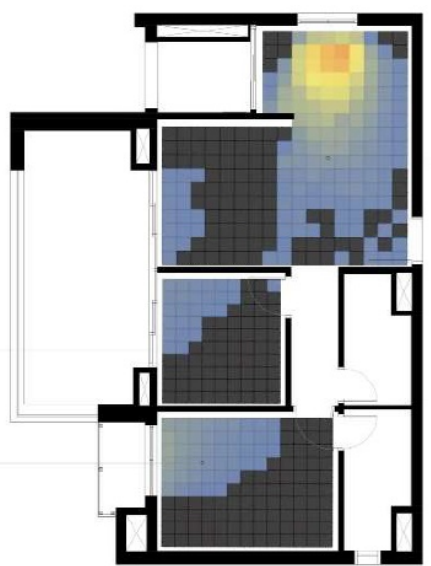

PLANTA UH $1^{\circ}$ PAVTO

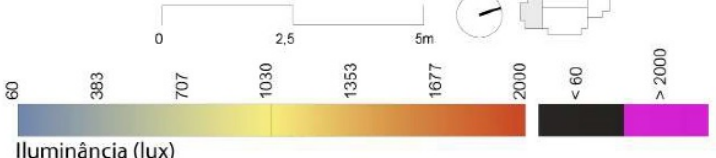

lluminância (lux)

\begin{tabular}{|c|c|c|c|c|c|}
\hline \multicolumn{6}{|c|}{ ANÁLISE DE ILUMINÂNCIAS - LUZ NATURAL AMBIENTES INTERNOS } \\
\hline \multicolumn{6}{|c|}{ data: 23/abr. horário: 15:30 } \\
\hline Ambiente & $\begin{array}{c}\text { Relação área } \\
\text { piso/aberturas }\end{array}$ & llum. média & $\begin{array}{l}\text { Ilum. entre } \\
60 \mathrm{e} 2000 \mathrm{~lx}\end{array}$ & $\underset{<60 \mid x}{\text { llum. }}$ & $\begin{aligned} & \text { Ilum. } \\
> & 2000 \mathrm{Ix}\end{aligned}$ \\
\hline 01 & $27,01 \%$ & $204,24 \mathrm{Ix}$ & $63,1 \%$ & $37,8 \%$ & - \\
\hline 02 & $60,48 \%$ & $45,26 \mathrm{Ix}$ & $28,9 \%$ & $71,1 \%$ & - \\
\hline 03 & $30,88 \%$ & $71,89 \mathrm{~lx}$ & $35,4 \%$ & $64,6 \%$ & - \\
\hline
\end{tabular}

Fonte: Boscardin (2021). 
Figura 11: análises de iluminâncias - UH 03, localizada no $1^{\circ}$ pavimento, em 23 de outubro - 9:30 /15:30 H.
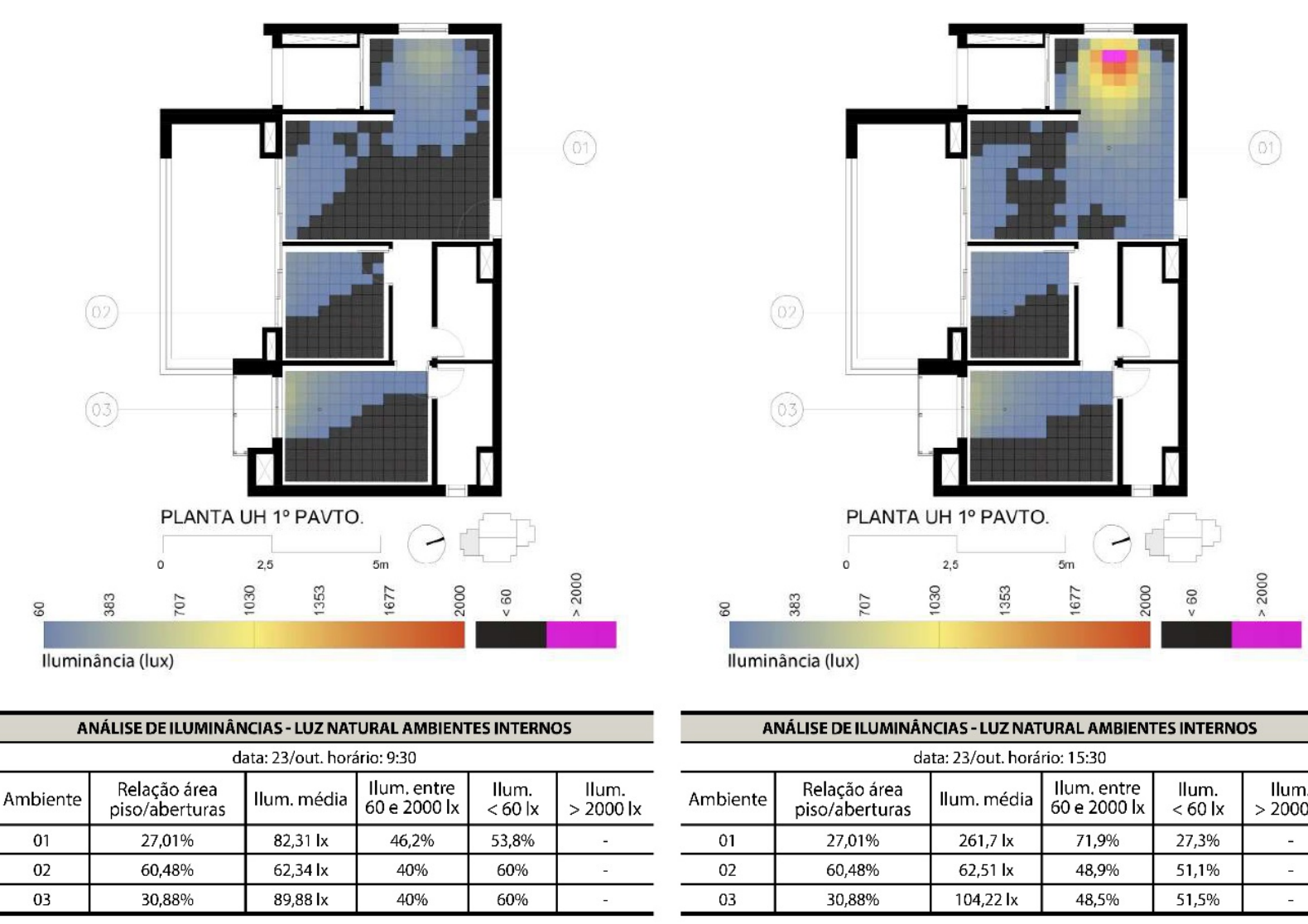

Fonte: Boscardin (2021).

\section{ANÁLISE E DISCUSSÃO DOS RESULTADOS OBTIDOS}

Os resultados das simulações dedicadas à unidade habitacional UH 01 (Figuras 06 e 07), mostram que durante as datas e horários determinados para a execução do experimento, as iluminâncias médias dos ambientes internos analisados se encontram em uma faixa compreendida entre os 157 e $381 \mathrm{~lx}$, valores acima dos $120 \mathrm{Ix}$, que representa uma iluminância de classe "superior" conforme o estabelecido pela NBR 15575 (Tabela 02). Apenas na sala de Estar/Cozinha (Ambiente 01), próximo a janela voltada para a face leste, foi registrado na simulação referente à manhã do dia 23 de outubro, uma iluminância superior aos $2000 \mathrm{Ix}^{3}$. Também é possível notar-se que em alguns pontos dos ambientes foram registrados valores situados abaixo dos 60 Ix (iluminância mínima recomendada pela norma). No entanto, como a NBR 15575 considera válida apenas a iluminância registrada no ponto central de cada ambiente, valores como estes, registados em pontos localizados em áreas periféricas, não exercem influência significativa sobre os resultados.

Na unidade UH 02 (Figuras 08 e 09), os mapas de iluminância para cada um dos ambientes apresentam padrões semelhantes aos observados na UH 01, contidos, porém, em uma faixa de maior amplitude, entre os 116 e $418 \mathrm{~lx}$ (em grande parte das áreas, acima dos $120 \mathrm{~lx}$, que representa o nível de iluminância superior, segundo a NBR 15575). De maneira geral, apesar do aumento de áreas, ainda que periféricas, onde os valores de iluminância se situam abaixo dos $60 \mathrm{~lx}$, os valores médios mais altos obtidos na simulação desta unidade indicam estar relacionados com as incidências captadas no ambiente 01, em área próxima a janela voltada ao oeste. As semelhanças dos mapas de iluminância dos ambientes 02 e 03 (dormitórios) das UH 01 e UH02, mesmo que estas apresentem orientações opostas à trajetória solar, indica que os sombreamentos ocasionados pelos terraços cobertos, que precedem as aberturas destes ambientes, influenciam de maneira direta na configuração dos resultados obtidos.

A unidade UH 03 (Figuras 10 e 11) está localizada no primeiro pavimento com aberturas orientadas para os quadrantes Sul e Oeste e apresenta um mapeamento de iluminâncias com valores médios situados em uma faixa compreendida entre os 45 e $261 \mathrm{~lx}$. O posicionamento desta unidade (orientação e altura) indica que a iluminação natural, obtida primordialmente de maneira indireta, é parcialmente obstruída pelas edificações vizinhas. Em consequência, em todos os ambientes registra-se um aumento significativo de áreas nas quais 
as iluminâncias estão situadas abaixo do valor mínimo de $60 \mathrm{~lx}$, inclusive nas proximidades dos pontos centrais de diversos ambientes, o que, segundo a NBR, é um parâmetro chave na qualificação dos padrões de iluminância interna.

A síntese dos dados obtidos nos processos de simulação, por meio da demonstração das iluminâncias médias gerais (Gráfico 02), porcentagens de áreas com iluminâncias situadas entre 60 e 2000 Ix (Gráfico 03), bem como aquelas com marcas inferiores ao limite mínimo, determinado pela NBR 15575, de 60 lux (Gráfico 04), indica que nas unidades habitacionais localizadas em pavimentos altos, livres do bloqueio da luz solar por interferência das edificações circundantes (UH 01 e UH 02), as iluminâncias médias alcançam valores elevados, significativamente acima do marco correspondente à classificação superior (120 Ix), de acordo com a NBR 15575.

Mesmo que estas unidades tenham orientações divergentes em relação à trajetória solar, com uma recebendo maiores níveis de luz solar direta (UH 01) e outra majoritariamente por processo de difusão atmosférica (UH 02), nota-se que ambas apresentam mais de $80 \%$ das áreas analisadas compreendidas em uma faixa de iluminância situada entre os 60 e $2000 \mathrm{~lx}$.

Na unidade habitacional situada no pavimento tipo mais baixo (UH 03), dotada de orientação solar onde a iluminação natural se dá sobretudo por difusão atmosférica e reflexão, suscetível ainda a interferências devido ao entono edificado, nota-se uma queda acentuada da iluminância média (Gráfico 02) quando comparada ao valor registrado na unidade mais iluminada (UH01). O decréscimo da qualidade da iluminação natural nesta unidade também é corroborado pela expressiva diminuição do percentual de áreas onde a medição de iluminâncias se concentram entre os 60 e 2000 Ix (Gráfico 03): se nas unidades posicionadas no pavimento mais alto as porcentagens médias encontram-se acima dos 80\%, na UH 03 este registro alcança apenas os 56,32\%, deixando o restante das áreas com iluminâncias abaixo do valor mínimo determinado pela NBR 15575 (Gráfico 04).

Gráficos 02, 03 e 04: síntese dos dados obtidos nos processos de simulação
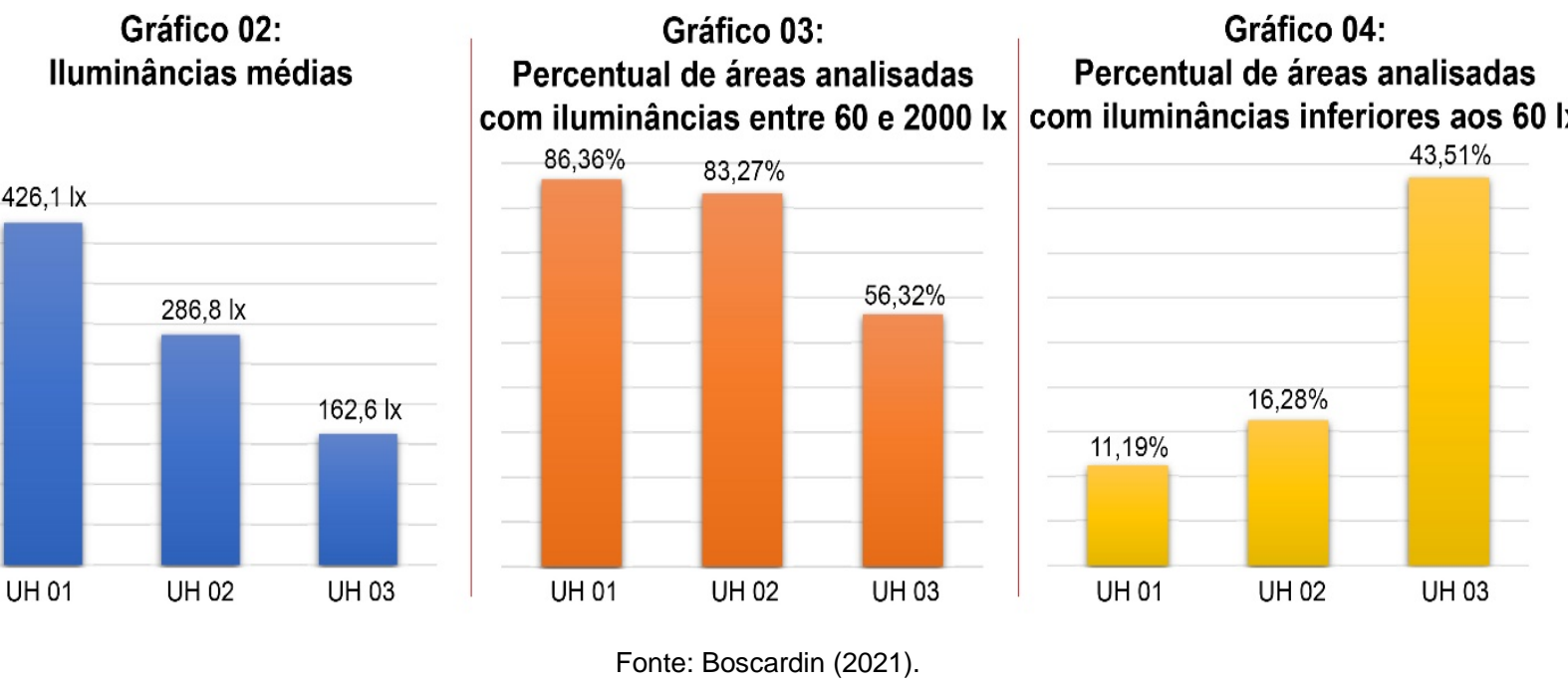

Fonte: Boscardin (2021).

\section{CONCLUSÃO}

Ao analisar os padrões de iluminância no interior das unidades habitacionais de um exemplar projetado e construído durante o período de vigência do COESP (1992-2017), o experimento aqui apresentado indica que o principal dispositivo associado ao desempenho lumínico natural empregado por esta Lei (representação do "Espaço I"), se mostra ineficiente, por não fornecer condições equivalentes de acesso à luz natural à totalidade das unidades habitacionais que compõem um edifício vertical, independentemente das características de entorno, orientação solar ou altura do pavimento em que estas se localizem.

Os processos de simulação e análise constantes deste artigo indicam que a falha metodológica na configuração deste instrumento de natureza prescritiva está na consideração apenas da relação entre recuos e gabarito, deixando de fora da equação parâmetros elementares, como a orientação das aberturas face à trajetória solar ${ }^{4}$ e as relações volumétricas e espaciais do edifício com seu o entorno imediato. 
A leitura e exame do COESP indica outra inconsistência relacionada ao satisfatório acesso à luz natural: a inexistência de conexão entre o dimensionamento mínimo das aberturas destinadas a iluminação e a formulação do "Espaço I", de maneira que a proposição de aberturas que excedessem a área mínima determinada, e que naturalmente propiciassem maiores ganhos de iluminação, não eram consideradas como parâmetros válidos para a definição desta representação.

Dando a devida importância às limitações tecnológicas existentes na época de vigência da legislação analisada, além das diversas demandas multidisciplinares inerentes à produção arquitetônica ligada ao mercado imobiliário, é possível depreender que a resolução de questões voltadas ao conforto ambiental em edifícios verticais de uso residencial, por meio de metodologias estritamente prescritivas, conduziram a um panorama onde a apreciação dos fatores bioclimáticos durante o decorrer do processo projetual fossem relegadas a um segundo plano, de modo que a aplicação de uma sequência de fórmulas, e a subsequente acomodação das representações gráficas resultantes e necessárias entre o volume do edifício e os limites do terreno onde este se inseria, encerravam as preocupações, por parte de projetistas, construtores e agentes públicos, com esta temática.

O novo Código de Obras e Edificações da Cidade de São Paulo, válido desde 2017 e formulado devido a promulgação do atual Plano Diretor, aprovado em 2014, modificou de maneira sensível as diretrizes relacionadas ao conforto ambiental das edificações, abolindo inclusive as representações da Faixa "A" e do Espaço "l". Segundo o novo Código, as questões relativas ao conforto ambiental devem ser aferidas preferencialmente por normas técnicas, como a NBR 15575, que regula o desempenho de edificações habitacionais por meio de métodos de avaliação que consideram válidos processos de simulação similares aos apresentados neste artigo.

No que diz respeito ao reconhecimento de ganhos relacionados ao conforto ambiental e à eficiência energética em edifícios residenciais, a efetividade das metodologias propostas pelo atual Código de Obras e Edificações da Cidade de São Paulo poderá ser estudada com maior precisão em um futuro próximo, após a conclusão e ocupação de um número significativo de edifícios projetados e construídos sob esta nova Lei. Isso tornará possível a realização de estudos sobre o real impacto destas metodologias, além de análises sobre a interação entre as novas edificações com um contexto urbano já consolidado, instituído a partir da consideração de instrumentos normativos que já se encontram fora de uso.

\section{AGRADECIMENTOS}

Os autores agradecem o apoio financeiro do Instituto Presbiteriano Mackenzie e a contribuição fundamental do escritório Königsberger Vannucchi Arquitetos Associados durante o desenvolvimento desta pesquisa.

\section{REFERÊNCIAS}

ASSOCIAÇÃO BRASILEIRA DE NORMAS TÉCNICAS. NBR 15.575-1: Edifícios habitacionais - Desempenho - parte 1: Requisitos gerais. Rio de Janeiro, 2013.

BLOCH, L. L.; BOTELHO, M. H. C. Código de Obras e Edificações do Município de São Paulo - comentado e criticado. São Paulo: Pini, 1993. 293 p.

BOSCARDIN, L. Königsberger Vannucchi arquitetos associados: simulações paramétricas e análises de desempenho lumínico de edifícios residenciais produzidos entre 1992 e 2017 na cidade de São Paulo. Tese (Doutorado), Programa de Pós-graduação em Arquitetura e Urbanismo, Faculdade de Arquitetura e Urbanismo, Universidade Presbiteriana Mackenzie, São Paulo, 2021.

CARLO, J. C. ; LAMBERTS, R. Parâmetros e métodos adotados no regulamento de etiquetagem da eficiência energética de edifícios - parte 1: método prescritivo. Disponível em https://doi.org/10.1590/S1678-86212010000200001. Acesso em 18.set.2020.

EMPRESA BRASILEIRA DE ESTUDOS DE PATRIMÔNIO (EMBRAESP). Relatórios Anuais - 1985 - 2017. Disponíveis em https://embraesp.com.br. Acesso em 18.set.2020.

FIGUEIREDO, E C. A abordagem sustentável da luz natural: análise do desenho de vãos e eficiência dos vedos translúcidos e transparentes em edifícios das cidades de São Paulo, Berlim e Frankfurt am Main durante as últimas décadas do século $X X$ e primeira década do século $X X I$. Dissertação (mestrado), Faculdade de Arquitetura e Urbanismo, Universidade Presbiteriana Mackenzie, São Paulo, 2011.

FREITAS JÚNIOR, R. G. Legislação e ocupação urbana em lotes privados do centro de São Paulo no século XX. Dissertação (Mestrado), Escola Politécnica da Universidade de São Paulo, Departamento de Engenharia de Construção Civil, São Paulo, 2008. 
GONÇALVES, J. C. S.; DOLCE, M.; MÜLFARTH, R. C. K.; LIMA, E. G.; FERREIRA, A.; MICHALSKY, R. N. The thermal environment in the high-density tall building from the Brazilian bioclimatic modernism: living in the COPAN building. In: INTERNATIONAL CONFERENCE ON PASSIVE AND LOW ENERGY ARCHITECTURE (PLEA). Proceedings of PLEA: Smart and healthy within the two-degree limit. Hong Kong: 2018, s/n.

HAYMAKER, J.; BERNAL, M.; MARSHALL, M.; OKHOYA, V.; SZILASI, A.; REZAEE, R.; CHEN, C.; SALVESON, A.; BRECHTEL, J.; DECKINGA, L.; HASAN, H.; EWING, P.; WELLE, B.. Design space construction: a framework to support collaborative, parametric decision making. ITcon, v. 23, Jun. 2018, pp. 157-178. Disponível em: http://www.itcon.org/2018/8. Acesso em 24.out.2019.

HEPNER, A. Desenho urbano, capital e ideologia em São Paulo - centralidade e forma urbana na marginal do rio Pinheiros. Dissertação (Mestrado). Programa de Pós-graduação em Arquitetura e Urbanismo, Faculdade de Arquitetura e Urbanismo, Universidade de São Paulo (FAU-USP), São Paulo, 2010.

HOPPE, S. B.; ALVAREZ, C. E.; LARANJA, A. C. Iluminação natural e legislação urbana: a experiência de Domingos Martins - ES (Brasil). In: EURO ELECS 2015 - Connecting People and Ideas. Proceedings of ...... Guimarães, Portugal: ELECS, 2015, pp. 1734-1744.

MASCARÓ, L.; ELVIRA, A. R. Luz, Clima e Arquitetura. 3. ed. São Paulo: Nobel, 1983.

MORAES, S. R. C. O arquiteto e o mercado imobiliário residencial na cidade de São Paulo no século XXI (2000-2011). 2013. Tese (Doutorado), Programa de Pós-graduação em Arquitetura e Urbanismo, Faculdade de Arquitetura e Urbanismo, Universidade Presbiteriana Mackenzie, São Paulo, 2013.

SÃO PAULO (Município de). Ato $n^{\circ}$ 663, de 10 de agosto de 1934. Aprova a consolidação do Código de Obras "Arthur Saboya" (lei no 3.427 , de 19 de novembro de 1929) abrangendo todas as disposições constantes de Leis e Atos, em vigor nesta data, referentes a construções, arruamentos etc. Disponível em <http://legislacao.prefeitura.sp.gov.br/leis/ato-gabinete-do-prefeito-663-de-10-de-agosto-de-1934> Acesso em 21.nov.2020.

SÃO PAULO (Município de). Lei n. 7.805, de 1 de novembro de 1972. Dispõe sobre o parcelamento, uso e ocupação do solo do município, e dá outras providências. Diário Oficial, São Paulo, 3 nov. 1972, f. 1.

SÃO PAULO (Município de). Lei n. 8.266, de 20 junho de 1975. Aprova o código de edificações, e dá outras providências. Diário Oficial, São Paulo, 21 jun. 1975, f. 1

SÃO PAULO (Município de). Lei n. 11.228, de 25 de junho de 1992. Dispõe sobre as regras gerais e específicas a serem obedecidas no projeto, licenciamento, execução, manutenção e utilização de obras e edificações, dentro dos limites dos imóveis, revoga a Lei n. 8.266/1975, com as alterações adotadas por leis posteriores, e dá outras providências. Diário Oficial, São Paulo, 26 de jun. 1992, f. 1.

SÃO PAULO (Município de). Lei n. 16.050, de 31 de julho de 2014. Aprova a Política de Desenvolvimento Urbano e o Plano Diretor Estratégico do Município de São Paulo e revoga a Lei no 13.430/2002. Diário Oficial, São Paulo, $1^{\circ}$ ago. 2014 , f.1.

SÃO PAULO (Município de). Lei no 16.642, de 9 de maio de 2017. Aprova o Código de Obras e Edificações do Município de São Paulo; introduz alterações nas Leis $n^{\circ} 15.150$, de 6 de maio de 2010, e n 15.764 , de 27 de maio de 2013. Diário Oficial, São Paulo, 10 mai. 2017, f. 1.

\section{NOTAS}

${ }^{1}$ O COESP de 1992 exigia que edifícios residenciais com altura superior aos 80 metros (geralmente, o equivalente a 27 pavimentos) deveriam obrigatoriamente incluir uma segunda escada de emergência enclausurada (HEPNER, 2010, p.254). O acréscimo na área construída comum e a consequente diminuição das áreas privativas (vendáveis) geralmente levavam a não adoção de gabaritos superiores a este limite.

${ }^{2}$ Parâmetros utilizados nos processos de modelagem e calibragem das ferramentas de simulação.

${ }^{3}$ No que diz respeito ao ofuscamento ou aquecimento involuntário devido à ocorrência de iluminâncias superiores aos 2000 lux, registros acima desta marca, quando detectados, em geral localizam-se em posições próximas as aberturas dos ambientes onde observados. Desta forma, situações de aquecimento involuntário ou ofuscamento podem ser corrigidas de maneira simples, por meio do fechamento parcial das venezianas que integram os caixilhos ou através da adição de cortinas.

${ }^{4} \mathrm{Em}$ período anterior o posicionamento das aberturas em relação à trajetória solar era uma fator a ser obrigatoriamente observado durante o desenvolvimento projetual de edifícios residenciais verticais; o Código de Obras da Cidade de São Paulo, vigente entre 1975 e 1992, indicava que não eram "consideradas para efeito de insolação, iluminação e ventilação de dormitórios, as aberturas voltadas para o Sul, cujos planos façam ângulo menor do que $30^{\circ} \mathrm{com}$ a direção Leste-Oeste" (São Paulo (SP), 1975); esta regra, porém, foi revogada pelo COESP de 1992.

NOTA DO EDITOR (*): O conteúdo do artigo e as imagens nele publicadas são de responsabilidade do(s) autor(es). 